\title{
Impact of routine invasive strategy on outcomes in patients with non-ST-segment elevation myocardial infarction during 2005-2014: A report from the Polish Registry of Acute Coronary Syndromes (PL-ACS)
}

Łukasz Piątek ${ }^{1,2}$, Krzysztof Wilczek³ ${ }^{3}$ Jacek Kurzawski², Marek Gierlotka ${ }^{3,4}$, Mariusz Gąsior ${ }^{3}$, Lech Poloński ${ }^{3}$, Marcin Sadowski ${ }^{1}$

${ }^{1}$ The Faculty of Medicine and Health Sciences, The Jan Kochanowski University, Kielce, Poland ${ }^{2} 2^{\text {nd }}$ Department of Cardiology, Swietokrzyskie Cardiology Center, Kielce, Poland

${ }^{3} 3^{\text {rd }}$ Department of Cardiology, School of Medicine with the Division of Dentistry in Zabrze, Medical University of Silesia in Katowice, Silesian Center for Heart Disease, Zabrze, Poland ${ }^{4}$ Department of Cardiology, University Hospital, Institute of Medicine, University of Opole, Poland

\begin{abstract}
Background: Non-ST-segment elevation myocardial infarction (NSTEMI) has become the most frequently encountered type of myocardial infarction. The patient clinical profile and management has evolved over the past decade. As there is still a scarcity of data on the latest trends in NSTEMI, changes herein were observed and assessed in the treatment and outcomes in Poland between 2005 and 2014. Methods: A total of 197,192 patients with NSTEMI who enrolled in the Polish Registry of Acute Coronary Syndromes (PL-ACS) between 2005 and 2014 were analyzed. In-hospital and 12-month mortality
\end{abstract} were assessed.

Results: Coronary angiography use increased from 35.8\% in 2005-2007 to 90.7\% in 2012-2014 $(p<0.05)$, whereas percutaneous coronary intervention increased from $25.7 \%$ in 2005-2007 to $63.6 \%$ in 2012-2014 ( $p<0.05)$. There was a 50\% reduction in in-hospital mortality (from $5.6 \%$ in $2005-2007$ to $2.8 \%$ in 2012-2014; $p<0.05$ ) and a $30 \%$ reduction in 1-year mortality (from $19.4 \%$ in 2005-2007 to 13.7\% in 2012-2014; $p<0.05$ ). A multivariate analysis confirmed an immense impact of invasive strategy on patient prognosis during in-hospital observation with an odds ratio (OR) of 0.31 (95\% confidence interval [CI] 0.29-0.33; $p<0.05$ ) as well as during the 12-month observation with an OR of 0.51 (95\% CI 0.49-0.52; $p<0.05)$.

Conclusions: Over the past 10 years, an important advance in the management of NSTEMI has taken place in Poland. Routine invasive strategy resulted in a significant decrease in mortality rates in all groups of NSTEMI patients. (Cardiol J 2020; 27, 5: 583-589)

Key words: non-ST-elevation myocardial infarction, invasive strategy, percutaneous coronary intervention, outcomes, temporal trends

Address for correspondence: Dr. Łukasz Piątek, $2^{\text {nd }}$ Department of Cardiology, Swietokrzyskie Cardiology Center, ul. Grunwaldzka 45, 25-715 Kielce, Poland, tel: 504590 245, fax: +48 413671 456, e-mail: piatas22@op.pl 


\section{Introduction}

Non-ST-segment elevation myocardial infarction (NSTEMI) represents the majority of all MI cases. In Western Europe, NSTEMI accounts for over $60 \%$ of all MI cases. Dynamic changes in the clinical profile and treatment strategy have been observed in recent years. Contemporary analyses for a wide national population are scarce.

The analysis of clinical characteristics, treatment strategies and outcomes in almost 200,000 NSTEMI cases registered in the Polish Registry of Acute Coronary Syndromes (PL-ACS) between 2005 and 2014 are presented.

\section{Methods}

The study population was drawn from 463 hospitals in Poland that provide care to patients with MIs. The population consists of patients admitted with a diagnosis of NSTEMI according to the European Society of Cardiology guidelines [1, 2]. The study covers a 10-year period from 2005 to 2014 . Contribution to the study was voluntary; nevertheless, half of all estimated NSTEMI cases in Poland during the study time period were included. The study complies with the Declaration of Helsinki and was approved by the PL-ACS Registry committee.

Data were collected from PL-ACS Registry questionnaires that include variables on demographic factors (gender, age), risk factors (smoking, hypertension, hypercholesterolemia, diabetes mellitus and obesity), previous coronary incidences and related procedures (MI, percutaneous coronary intervention [PCI], coronary artery bypass grafting), clinical presentation on admission (Killip class, heart rate, systolic blood pressure), electrocardiographic abnormalities, left ventricular ejection fraction, coronary angiography (CA), coronary intervention details, and in-hospital and post-discharge treatment. The mortality rate was evaluated for the in-hospital observation period as well as for 30-day, 6-month and 12-month followup periods.

\section{Statistical analysis}

The gender groups were analyzed separately and subsequently compared to each other. To investigate the impact of age on outcomes, the analysis was conducted in age groups $(<55,55-64,65-74$, $\geq 75$ years) as well as in consecutive decades of life. Changes over time were investigated using the following two models: a comparison between subgroups in marginal 3-year intervals (2005-2007 and 2012-2014) and an evaluation of temporal trends over a 10-year period.

Categorical data are presented as numbers and percentages while continuous data are presented as the median or arithmetic mean \pm standard deviation (SD). Differences in categorical variables were tested using the $\chi^{2}$ test with Pearson modification, whereas in continuous variables differences were tested with the Student t-test. A two-sided $p$ value $\leq 0.05$ was considered significant. Trend importance was verified by the Cochran-Armitage test for categorical data and the Jonckheere-Terpstra test for continuous data. A logistic regression was used to identify variables that independently contributed to mortality.

\section{Results}

A total of 197,192 patients (including 77,550 women, 39.3\%) hospitalized in Poland due to NSTEMI between 2005 and 2014 were included in the analysis. The contribution of younger patients (under 55) decreased compared to older patients. The average age of males increased from 65 to 66 while in women it was stable at 72 . Nevertheless, men predominated in the group under 70 , whereas women did in the group over 70 .

The frequency of diabetes, arterial hypertension, obesity (in men only), and smoking (in women only) also increased. A history of prior coronary artery interventions (especially PCI) was more common in the later years were observed in this study (Table 1).

Over the last decade, NSTEMI treatment strategy has changed significantly. The frequency of coronary angiography increased from $35.8 \%$ in 2005-2007 up to $90.7 \%$ in 2012-2014; p $<0.05$. From 2012 to 2014, the gender disparity in CA implementation was still visible with $88.4 \%$ in women vs. $92.1 \%$ in men; $\mathrm{p}<0.05$. PCI use increased from $25.7 \%$ in $2005-2007$ to $63.6 \%$ in $2012-2014$; $\mathrm{p}<0.05$. From 2012 to 2014 we achieved 59.6\% in women and $66.1 \%$ in men; $p<0.05$. The most intensive growth of an invasive procedure use took place between 2007 and 2011. In later years, only a mild further increase was observed. In 2014, only $10.9 \%$ of women and $7.1 \%$ of men $(\mathrm{p}<0.05)$ were treated conservatively. Temporal trends in the invasive treatment of NSTEMI patients are presented in Figure 1.

The age group analysis revealed that the percentage of invasive treatment increased most in the oldest patients (over 75 years) and achieved a level of $80 \%$ in CA and $50 \%$ in PCI. Although differences 
Table 1. Clinical characteristics of non-ST-elevation myocardial infarction patients.

\begin{tabular}{|c|c|c|c|c|c|c|c|c|}
\hline \multirow[t]{2}{*}{ Clinical characteristics } & \multicolumn{3}{|c|}{ 2005-2007 } & \multicolumn{3}{|c|}{ 2012-2014 } & \multicolumn{2}{|c|}{$\begin{array}{c}2005-2007 \\
\text { vs. } 2012-2014\end{array}$} \\
\hline & Women & Men & $\mathbf{P}$ & Women & Men & $\mathbf{P}$ & Women & Men \\
\hline Age $<55$ years & $\begin{array}{c}1738 \\
(7.5 \%)\end{array}$ & $\begin{array}{c}6162 \\
(18.6 \%)\end{array}$ & $<0.05$ & $\begin{array}{c}1647 \\
(6.4 \%)\end{array}$ & $\begin{array}{c}5468 \\
(13.3 \%)\end{array}$ & $<0.05$ & $<0.05$ & $<0.05$ \\
\hline Age $\geq 7$ years & $\begin{array}{c}11208 \\
(48.3 \%)\end{array}$ & $\begin{array}{c}8746 \\
(26.4 \%)\end{array}$ & $<0.05$ & $\begin{array}{c}12098 \\
(47.4 \%)\end{array}$ & $\begin{array}{c}11571 \\
(28.1 \%)\end{array}$ & $<0.05$ & $<0.05$ & $<0.05$ \\
\hline Hypertension & $\begin{array}{c}17908 \\
(77.2 \%)\end{array}$ & $\begin{array}{c}22792 \\
(68.8 \%)\end{array}$ & $<0.05$ & $\begin{array}{c}20568 \\
(80.5 \%)\end{array}$ & $\begin{array}{c}31219 \\
(75.9 \%)\end{array}$ & $<0.05$ & $<0.05$ & $<0.05$ \\
\hline Diabetes & $\begin{array}{c}8180 \\
(35.3 \%)\end{array}$ & $\begin{array}{c}9623 \\
(23.7 \%)\end{array}$ & $<0.05$ & $\begin{array}{c}7865 \\
(37.3 \%)\end{array}$ & $\begin{array}{c}11999 \\
(29.2 \%)\end{array}$ & $<0.05$ & $<0.05$ & $<0.05$ \\
\hline Hyperlipidemia & $\begin{array}{c}10182 \\
(43.9 \%)\end{array}$ & $\begin{array}{c}11264 \\
(43.6 \%)\end{array}$ & 0.43 & $\begin{array}{c}1446 \\
(44.1 \%)\end{array}$ & $\begin{array}{c}18067 \\
(43.9 \%)\end{array}$ & 0.67 & 0.67 & 0.33 \\
\hline Current smoking & $\begin{array}{c}2403 \\
(10.4 \%)\end{array}$ & $\begin{array}{c}10595 \\
(32.0 \%)\end{array}$ & $<0.05$ & $\begin{array}{c}3340 \\
(13.1 \%)\end{array}$ & $\begin{array}{c}10989 \\
(26.7 \%)\end{array}$ & $<0.05$ & $<0.05$ & $<0.05$ \\
\hline Obesity & $\begin{array}{c}5879 \\
(25.4 \%)\end{array}$ & $\begin{array}{c}5143 \\
(15.5 \%)\end{array}$ & $<0.05$ & $\begin{array}{c}6391 \\
(25.0 \%)\end{array}$ & $\begin{array}{c}7807 \\
(19.0 \%)\end{array}$ & $<0.05$ & 0.40 & $<0.05$ \\
\hline Prior MI & $\begin{array}{c}5899 \\
(25.4 \%)\end{array}$ & $\begin{array}{c}10097 \\
(30.5 \%)\end{array}$ & $<0.05$ & $\begin{array}{c}5681 \\
(22.2 \%)\end{array}$ & $\begin{array}{c}10728 \\
(26.1 \%)\end{array}$ & $<0.05$ & $<0.05$ & $<0.05$ \\
\hline Prior PCl & $\begin{array}{c}736 \\
(3.2 \%)\end{array}$ & $\begin{array}{c}1680 \\
(5.1 \%)\end{array}$ & $<0.05$ & $\begin{array}{c}4301 \\
(16.8 \%)\end{array}$ & $\begin{array}{c}8534 \\
(20.8 \%)\end{array}$ & $<0.05$ & $<0.05$ & $<0.05$ \\
\hline Prior CABG & $\begin{array}{c}1321 \\
(5.7 \%)\end{array}$ & $\begin{array}{c}2764 \\
(8.3 \%)\end{array}$ & $<0.05$ & $\begin{array}{c}1092 \\
(4.3 \%)\end{array}$ & $\begin{array}{c}2755 \\
(6.7 \%)\end{array}$ & $<0.05$ & $<0.05$ & $<0.05$ \\
\hline
\end{tabular}

$\mathrm{CABG}$ - coronary artery bypass grafting; $\mathrm{MI}$ - myocardial infarction; $\mathrm{PCl}$ - percutaneous coronary intervention

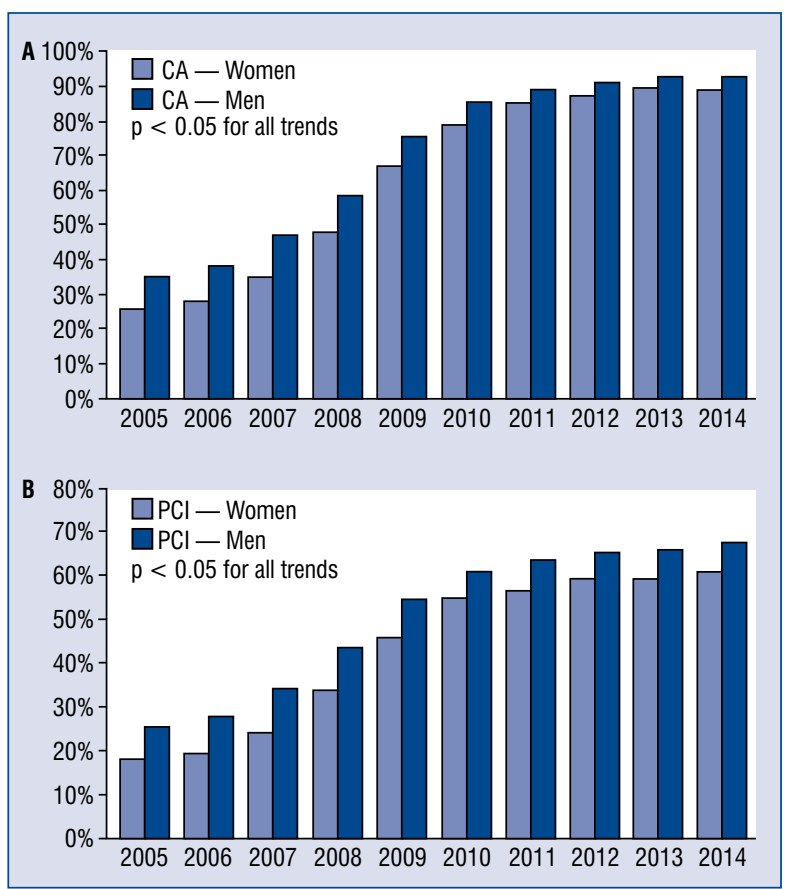

Figure 1. Temporal trends in utilization of coronary angiography (CA) (A) and percutaneous coronary intervention (PCI) (B). among the age groups diminished during the study, a slight disproportion still existed. In all age groups, invasive strategies were more widespread in men than in woman. Nevertheless, this disproportion has decreased in recent years (Fig. 2).

There have been significant changes in pharmacotherapy over the last decade, especially in the use of antiplatelet agents. The utilization of P2Y12-receptor blockers substantially increased from $51.0 \%$ in women and $59.1 \%$ in men from 2005 to 2007 to $92.9 \%$ in women and $93.2 \%$ in men $(\mathrm{p}<0.05)$. Ticlopidine, which was commonly used, was almost completely substituted by clopidogrel. In addition, during the last years a continuous shift from clopidogrel to ticagrelol or prasugrel was observed.

The management outcomes of NSTEMI patients have improved considerably over the last decade. In the present analysis, the risk of reinfarction was reduced from $4.5 \%$ in $2005-2007$ to $0.3 \%$ in $2012-2014(\mathrm{p}<0.05)$, and the risk of stroke was reduced from $0.5 \%$ in $2005-2007$ to $0.2 \%$ in 2012-2014 ( $\mathrm{p}<0.05)$. On the other hand, a side effect of the intensive invasive treatment application was observed, especially in the frequency of 


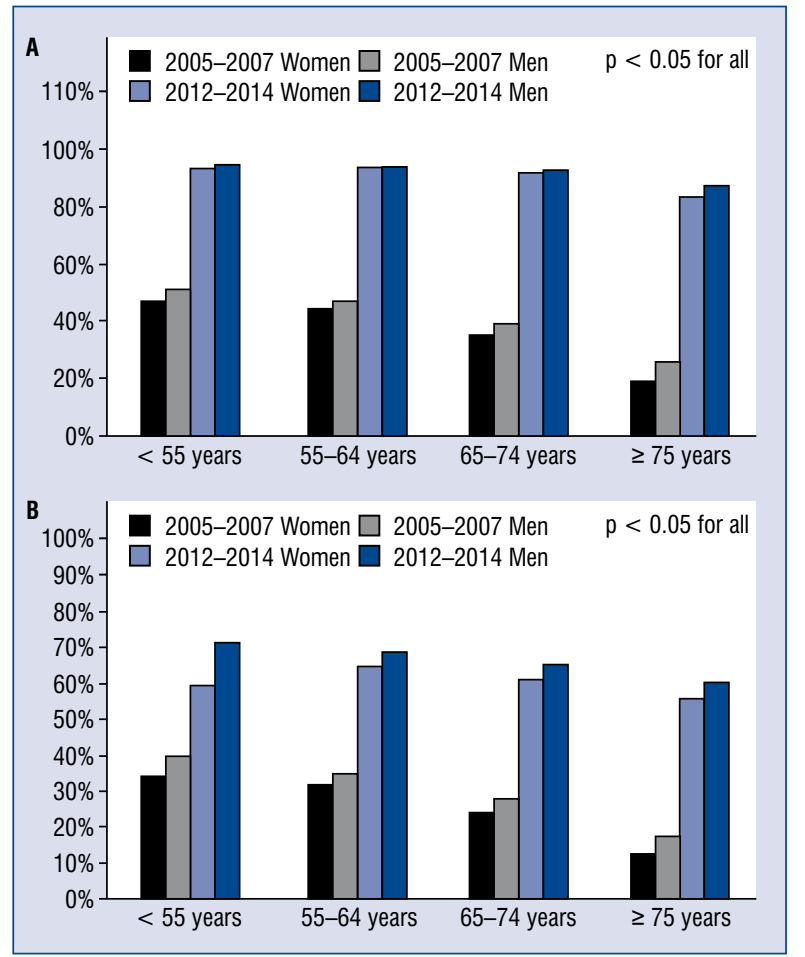

Figure 2. Percentage of coronary angiography (CA) (A) and percutaneous coronary intervention $(\mathrm{PCI})(\mathrm{B})$ in age groups.

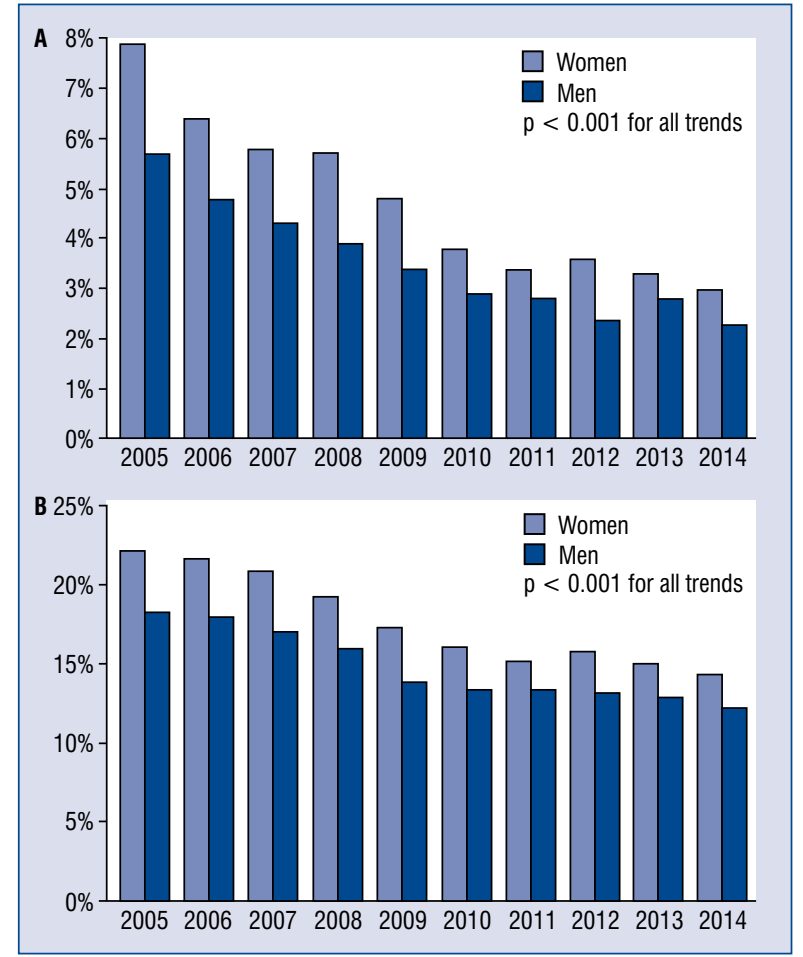

Figure 3. Temporal trends of in-hospital mortality (A) and 12-month mortality (B).

Table 2. Mortality rates by gender.

\begin{tabular}{|c|c|c|c|c|c|c|c|c|}
\hline \multirow[t]{2}{*}{ Mortality rates } & \multicolumn{3}{|c|}{ 2005-2007 } & \multicolumn{3}{|c|}{ 2012-2014 } & \multicolumn{2}{|c|}{$\begin{array}{l}2005-2007 \\
\text { vs. } 2012-2014\end{array}$} \\
\hline & Women & Men & $\mathbf{P}$ & Women & Men & $\mathbf{P}$ & Women & Men \\
\hline In-hospital mortality & $\begin{array}{c}1541 \\
(6.6 \%)\end{array}$ & $\begin{array}{c}1633 \\
(4.9 \%)\end{array}$ & $<0.05$ & $\begin{array}{c}851 \\
(3.3 \%)\end{array}$ & $\begin{array}{c}1026 \\
(2.5 \%)\end{array}$ & $<0.05$ & $<0.05$ & $<0.05$ \\
\hline 30-day mortality & $\begin{array}{c}2267 \\
(9.8 \%)\end{array}$ & $\begin{array}{c}2571 \\
(7.8 \%)\end{array}$ & $<0.05$ & $\begin{array}{c}1686 \\
(6.6 \%)\end{array}$ & $\begin{array}{c}2101 \\
(5.1 \%)\end{array}$ & $<0.05$ & $<0.05$ & $<0.05$ \\
\hline 6-month mortality & $\begin{array}{c}3988 \\
(17.2 \%)\end{array}$ & $\begin{array}{c}4586 \\
(13.8 \%)\end{array}$ & $<0.05$ & $\begin{array}{c}2997 \\
(11.7 \%)\end{array}$ & $\begin{array}{c}3994 \\
(9.7 \%)\end{array}$ & $<0.05$ & $<0.05$ & $<0.05$ \\
\hline 12-month mortality & $\begin{array}{c}5005 \\
(21.6 \%)\end{array}$ & $\begin{array}{c}5897 \\
(17.8 \%)\end{array}$ & $<0.05$ & $\begin{array}{c}3865 \\
(15.1 \%)\end{array}$ & $\begin{array}{c}5258 \\
(12.8 \%)\end{array}$ & $<0.05$ & $<0.05$ & $<0.05$ \\
\hline
\end{tabular}

major bleeding $(0.7 \%$ in $2005-2007$ vs. $1.2 \%$ in 2012-2014; $\mathrm{p}<0.05$ ).

In-hospital mortality decreased by $50 \%$ (from $5.6 \%$ in $2005-2007$ to $2.8 \%$ in $2012-2014 ; \mathrm{p}<0.05$ ) and 1 -year mortality by up to $30 \%$ (from $19.4 \%$ in 2005-2007 to $13.7 \%$ in 2012-2014; $p<0.05$ ) (Fig. 3). These positive tendencies are apparent in all age groups and genders (Table 2). Mortality rates in the four age groups (under 55, 55-64, 65-74, 75 and over) are presented in Figure 4.
A multivariable analysis showed that the impact of the invasive strategy on mortality decrease was immense, with a 3-fold improvement in outcomes in short-term observation and a 2 -fold improvement in long-term observation (Tables 3 and 4).

\section{Discussion}

The clinical characteristics and management of NSTEMI patients together with treatment 


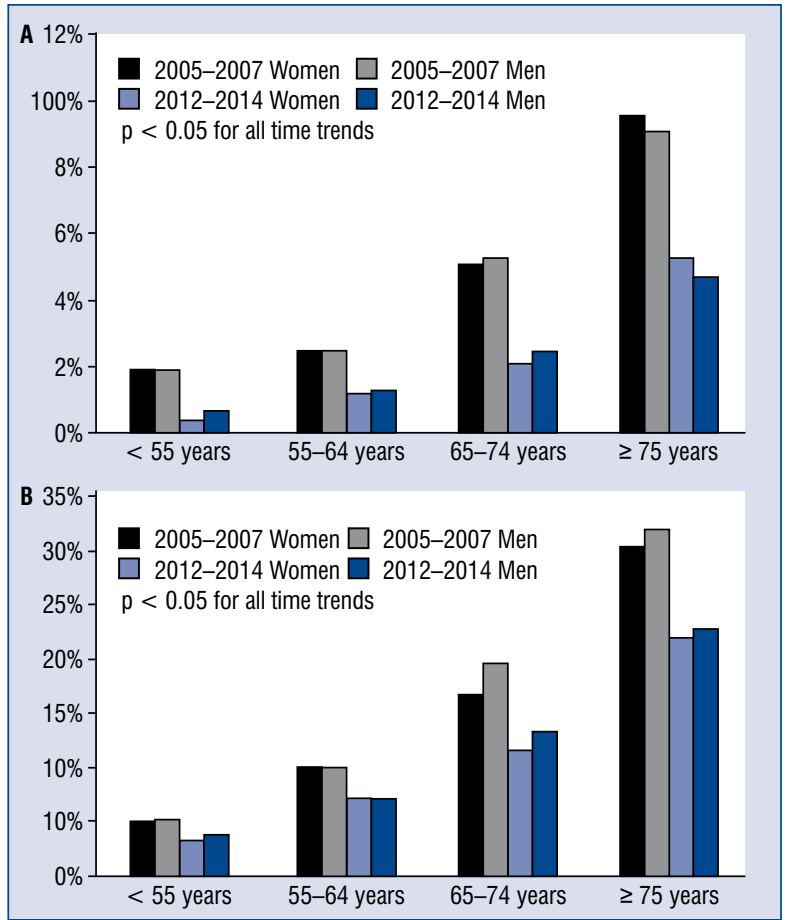

Figure 4. In-hospital mortality (A) and 12-month mortality $(\mathbf{B})$ in age groups. outcomes have significantly changed all over the world in recent years [3-5]. In Poland, as in many other countries, NSTEMI has become the most common type of MI.

According to many previous reports on NSTEMI, there are common trends in the baseline clinical profile of patients. The prevalence of major atherosclerosis risk factors like arterial hypertension, diabetes, obesity and chronic kidney disease is still increasing $[4,5]$. Similar trends were observed in the present study. Contrary to findings in other countries, the mean age of NSTEMI patients in Poland increased, especially in men. Presumably this is a result of a noticeable smoking decrease and better pharmacological risk factor control, i.e., hypercholesterolemia and arterial hypertension. Over the last 10 years, some important changes in medical therapy have taken place. The vast majority of patients received P2Y12-receptor blockers. Interestingly, from 2005 to 2007 many patients were still administered ticlopidine, which was gradually substituted by clopidogrel and later by new drugs such as ticagrelol, according to the European Society of Cardiology guidelines [1, 2].

Table 3. Multivariate analysis (in-hospital mortality).

\begin{tabular}{lccc}
\hline & P & OR & OR (95\% CI) \\
\hline Invasive treatment & $<0.0001$ & 0.31 & $0.31(0.29-0.33)$ \\
Hypercholesterolemia & $<0.0001$ & 0.73 & $0.73(0.69-0.77)$ \\
Hypertension & $<0.0001$ & 0.73 & $0.73(0.69-0.78)$ \\
Previous PCI & $<0.0001$ & 0.80 & $0.80(0.73-0.88)$ \\
Previous CABG & 0.0006 & 0.80 & $0.80(0.71-0.91)$ \\
Current smokers & 0.6776 & 1.02 & $1.02(0.94-1.10)$ \\
Female (vs. male) & 0.4485 & 1.02 & $1.02(0.97-1.08)$ \\
Previous MI & 0.0255 & 1.07 & $1.07(1.01-1.14)$ \\
Diabetes & 0.0021 & 1.09 & $1.09(1.03-1.15)$ \\
Time to admission $>12$ h & 0.0030 & 1.09 & $1.09(1.03-1.16)$ \\
LVEF 35-50\% & 0.0240 & 1.10 & $1.10(1.01-1.20)$ \\
ST-T abnormalities in ECG & 0.0007 & 1.16 & $1.16(1.07-1.27)$ \\
Obesity & $<0.0001$ & 1.18 & $1.18(1.10-1.26)$ \\
No sinus rhythm in ECG & $<0.0001$ & 1.19 & $1.19(1.12-1.27)$ \\
Age (on each decade) & $<0.0001$ & 1.63 & $1.63(1.59-1.68)$ \\
LVEF < 35\% & $<0.0001$ & 2.31 & $2.31(2.11-2.53)$ \\
Prehospital cardiac arrest & $<0.0001$ & 2.37 & $2.37(2.09-2.69)$ \\
Killip 3 class & $<0.0001$ & 3.67 & $3.67(3.41-3.94)$ \\
IABP & $<0.0001$ & 3.89 & $3.89(3.23-4.69)$ \\
Killip 4 class & $<0.0001$ & 13.17 & $13.2(12.0-14.4)$ \\
\hline
\end{tabular}

CABG - coronary artery bypass grafting; $\mathrm{Cl}$ - confidence interval; ECG - electrocardiogram; IABP — intraaortic balloon pump; LVEF - left ventricular ejection fraction; $\mathrm{Ml}$ - myocardial infarction; $\mathrm{OR}$ - odds ratio; $\mathrm{PCl}$ - percutaneous coronary intervention 
Table 4. Multivariate analysis (12-month mortality).

\begin{tabular}{lccc}
\hline & P & OR & OR (95\% CI) \\
\hline Invasive treatment & $<0.0001$ & 0.51 & $0.51(0.49-0.52)$ \\
Hypercholesterolemia & $<0.0001$ & 0.81 & $0.81(0.79-0.83)$ \\
Previous CABG & $<0.0001$ & 0.84 & $0.84(0.80-0.88)$ \\
Hypertension & $<0.0001$ & 0.85 & $0.85(0.83-0.88)$ \\
Previous PCI & $<0.0001$ & 0.90 & $0.90(0.87-0.94)$ \\
Female (vs. male) & $<0.0001$ & 0.94 & $0.94(0.92-0.97)$ \\
Obesity & 0.37 & 0.99 & $0.99(0.96-1.02)$ \\
Time to admission $>12 \mathrm{~h}$ & 0.02 & 1.02 & $1.03(1.00-1.06)$ \\
Current smokers & 0.0005 & 1.07 & $1.06(1.03-1.10)$ \\
Previous MI & $<0.0001$ & 1.12 & $1.12(1.09-1.15)$ \\
ST-T abnormalities in ECG & $<0.0001$ & 1.14 & $1.15(1.11-1.19)$ \\
No sinus rhythm in ECG & $<0.0001$ & 1.15 & $1.14(1.11-1.18)$ \\
Diabetes & $<0.0001$ & 1.29 & $1.29(1.26-1.32)$ \\
LVEF 35-50\% & $<0.0001$ & 1.52 & $1.52(1.47-1.57)$ \\
Age (on each decade) & $<0.0001$ & 1.57 & $1.57(1.55-1.59)$ \\
Prehospital cardiac arrest & $<0.0001$ & 1.74 & $1.74(1.63-1.85)$ \\
Killip 3 class & $<0.0001$ & 1.98 & $1.98(1.91-2.06)$ \\
IABP & $<0.0001$ & 2.17 & $2.17(1.99-2.38)$ \\
LVEF < 35\% & $<0.0001$ & 2.67 & $2.67(2.57-2.78)$ \\
Killip 4 class & $<0.0001$ & 4.48 & $4.48(4.26-4.71)$ \\
\hline
\end{tabular}

CABG - coronary artery bypass grafting; $\mathrm{Cl}$ - confidence interval; ECG - electrocardiogram; IABP — intraaortic balloon pump; LVEF - left ventricular ejection fraction; $\mathrm{MI}$ - myocardial infarction; $\mathrm{OR}$ - odds ratio; $\mathrm{PCl}$ - percutaneous coronary intervention

The European Society of Cardiology-recommended implementation of a routine invasive strategy has been the most important change in NSTEMI treatment over the last 10 years $[1,2]$. A rapid increase in the number of $24 / 7$ catheterization centers in Poland (up to 150) enabled the successful introduction of this recommendation. The percentage of CAs as well as PCIs in NSTEMI patients in Poland reached the same level as countries in Western Europe such as France [4] and Denmark [6] as well as the United States [5]. Importantly, previously reported underutilization of an invasive strategy in women as well as in older patients was not as pronounced in Poland [7-11]. The significant advances in treatment have resulted in a spectacular decrease in mortality rates at an even higher rate than in previous analyses $[3-5,12,13]$.

In the multivariable analysis, the invasive strategy was the most important factor contributing to a better prognosis for in-hospital and 12-month observations. The advantages of invasive treatment were apparent in all patients regardless of age or gender. The final results are comparable to data from other countries that have successfully introduced contemporary guidelines [14].

\section{Limitations of the study}

This study has several limitations. PL-ACS is a voluntary, observational study, and not all hospitals treating NSTEMI in Poland participated in data collection. The present analysis was retrospective, and some potentially important parameters might not be included. Finally, this is a single country study; therefore, some trends should be interpreted with caution.

\section{Conclusions}

In Poland, outcomes of NSTEMI patients have improved substantially over the last 10 years due to the implementation of routine invasive treatment. The invasive approach was beneficial to all age groups and both genders.

\section{Conflict of interest: None declared}

\section{References}

1. Bassand JP, Hamm CW, Ardissino D, et al. Guidelines for the diagnosis and treatment of non-ST-segment elevation acute coronary syndromes. Task Force for Diagnosis and Treatment of 
Non-ST-Segment Elevation Acute Coronary Syndromes of European Society of Cardiology. Eur Heart J. 2007; 28(13): 1598-660.

2. Hamm CW, Bassand JP, Agewall S, et al. ESC Guidelines for the management of acute coronary syndromes in patients presenting without persistent ST-segment elevation: The Task Force for the management of acute coronary syndromes (ACS) in patients presenting without persistent ST-segment elevation of the European Society of Cardiology (ESC). Eur Heart J. 2011; 32(23): 2999-3054, doi: 10.1093/eurheartj/ehr236, indexed in Pubmed: 21873419.

3. Gierlotka M, Gąsior M, Wilczek K, et al. Temporal trends in the treatment and outcomes of patients With non-ST-segment elevation myocardial infarction in Poland from 2004-2010 (from the Polish Registry of Acute Coronary Syndromes). Am J Cardiol. 2012; 109(6): 779-786, doi: 10.1016/j.amjcard.2011.10.041, indexed in Pubmed: 22189010.

4. Puymirat E, Simon T, Cayla G, et al. Acute Myocardial Infarction: Changes in Patient Characteristics, Management, and 6-Month Outcomes Over a Period of 20 Years in the FAST-MI Program (French Registry of Acute ST-Elevation or Non-ST-Elevation Myocardial Infarction) 1995 to 2015. Circulation. 2017; 136(20): 1908-1919, doi: 10.1161/circulationaha.117.030798.

5. Khera S, Kolte D, Aronow WS, et al. Non-ST-elevation myocardial infarction in the United States: contemporary trends in incidence, utilization of the early invasive strategy, and inhospital outcomes. J Am Heart Assoc. 2014; 3(4), doi: 10.1161/ JAHA.114.000995, indexed in Pubmed: 25074695.

6. Mårtensson S, Gyrd-Hansen D, Prescott E, et al. Trends in time to invasive examination and treatment from 2001 to 2009 in patients admitted first time with non-ST elevation myocardial infarction or unstable angina in Denmark. BMJ Open. 2014; 4(1): e004052, doi: 10.1136/bmjopen-2013-004052, indexed in Pubmed: 24413349.

7. Bugiardini R, Yan AT, Yan RT, et al. Factors influencing underutilization of evidence-based therapies in women. Eur Heart J. 2011; 32(11): 1337-1344, doi: 10.1093/eurheartj/ehr027, indexed in Pubmed: 21383003.

8. Poon S, Goodman SG, Yan RT, et al. Bridging the gender gap: Insights from a contemporary analysis of sex-related differences in the treatment and outcomes of patients with acute coronary syndromes. Am Heart J. 2012; 163(1): 66-73, doi: 10.1016/j. ahj.2011.09.025, indexed in Pubmed: 22172438.

9. Malkin CJ, Prakash R, Chew DP. The impact of increased age on outcome from a strategy of early invasive management and revascularisation in patients with acute coronary syndromes: retrospective analysis study from the ACACIA registry. BMJ Open. 2012; 2(1): e000540, doi: 10.1136/bmjopen-2011-000540, indexed in Pubmed: 22344538.

10. Redfors B, Angerås $\mathrm{O}$, Råmunddal T, et al. Trends in Gender Differences in Cardiac Care and Outcome After Acute Myocardial Infarction in Western Sweden: A Report From the Swedish Web System for Enhancement of Evidence-Based Care in Heart Disease Evaluated According to Recommended Therapies (SWEDEHEART). J Am Heart Assoc. 2015; 4(7), doi: 10.1161/ /JAHA.115.001995, indexed in Pubmed: 26175358.

11. Darling CE, Fisher KA, McManus DD, et al. Survival after hospital discharge for ST-segment elevation and non-ST-segment elevation acute myocardial infarction: a population-based study. Clin Epidemiol. 2013; 5: 229-236, doi: 10.2147/CLEP.S45646, indexed in Pubmed: 23901296.

12. Alfredsson J, Lindbäck J, Wallentin L, et al. Similar outcome with an invasive strategy in men and women with non-ST-elevation acute coronary syndromes: from the Swedish Web-System for Enhancement and Development of Evidence-Based Care in Heart Disease Evaluated According to Recommended Therapies (SWEDEHEART). Eur Heart J. 2011; 32(24): 3128-3136, doi: 10.1093/eurheartj/ehr349, indexed in Pubmed: 21911338.

13. Kleopatra K, Muth K, Zahn R, et al. Effect of an invasive strategy on in-hospital outcome and one-year mortality in women with non-ST-elevation myocardial infarction. Int J Cardiol. 2011; 153(3): 291-295, doi: 10.1016/j.ijcard.2010.08.050, indexed in Pubmed: 20851476.

14. André R, Bongard V, Elosua R, et al. International differences in acute coronary syndrome patients' baseline characteristics, clinical management and outcomes in Western Europe: the EURHOBOP study. Heart. 2014; 100(15): 1201-1207, doi: 10.1136/ /heartjnl-2013-305196, indexed in Pubmed: 24790068. 